\title{
Patients with ST segment elevation myocardial infarction: moderating effect of perceived control on the relationship between depression and in-hospital complications
}

\author{
Mohannad Eid AbuRuziD
}

\begin{abstract}
Background: Cardiovascular diseases remain the top global killer, with nearly $80 \%$ of related mortalities occurring in developing countries. Over half of cardiovascular diseases' mortality is due to coronary heart disease, which is commonly linked to acute myocardial infarction. Psychological factors (i.e., depression and anxiety) after acute myocardial infarction are associated with higher levels of complications and mortality. Perceived control moderated the effect of anxiety on complications in different cardiac populations, but impacts on depression and complications after acute myocardial infarction are not well studied. This study explores the moderating effect of perceived control on the relationship between depression and complications after ST segment elevation myocardial infarction.
\end{abstract}

Methods: Three hundred patients with a confirmed diagnosis of ST segment elevation myocardial infarction participated in this prospective observational study. Patients answered socio-demographic data, the depression subscale of the Hospital Anxiety and Depression Scale (HADS), and the Control Attitude Scale-Revised (CAS-R) questionnaires. In-hospital complications and all other necessary data were extracted from medical records after discharge. Data were analyzed using logistic regression.

Results: $24 \%$ developed at least one complication. Patients with high depression scores (8-21) were more likely to develop complications $\left(x^{2}=34.15, p<.001\right)$ than those with low depression scores $(0-7)$. Patients with high levels of perceived control had lower levels of depression than those with low perceived control (mean [SD], 9.47 [6.43] vs. 12.31 [6.66], $p<.001)$. The results of logistic regression showed that perceived control moderated the association between depression and complications, since depression scores, perceived control scores, and the interaction between depression and perceived control were significant predictors of complications. Participants with high depression and low perceived control had the highest rate of complications (31.5\% vs. $15.4 \%, P<.001)$.

Conclusions: Depression increased complications after ST segment elevation myocardial infarction. Perceived control moderated this relationship. Assessment of depression and enhancement of perceived control in patients with acute myocardial infarction can decrease complications and improve outcomes.

Keywords: Acute myocardial infarction, Depression, Perceived control, Complications

(c) The Author(s). 2019 Open Access This article is distributed under the terms of the Creative Commons Attribution 4.0 International License (http://creativecommons.org/licenses/by/4.0/), which permits unrestricted use, distribution, and reproduction in any medium, provided you give appropriate credit to the original author(s) and the source, provide a link to the Creative Commons license, and indicate if changes were made. The Creative Commons Public Domain Dedication waiver (http://creativecommons.org/publicdomain/zero/1.0/) applies to the data made available in this article, unless otherwise stated. 


\section{Background}

Cardiovascular diseases (CVDs) are the most common cause of death worldwide [1]. In the US alone, there is more than 90 million diagnosed with at least one type of CVD [1]. Approximately $80 \%$ of all deaths nationwide due to CVDs occur in developing (low and middle income) countries [1]. In the developing countries of the Middle East, mortality rates due to CVDs are increasing [2]; in Jordan, $35 \%$ of all deaths occur as a result of CVDs [3].

More than half of all CVDs are due to coronary heart disease (CHD) [1]. Every $40 \mathrm{~s}$ an American will have an acute myocardial infarction (AMI) due to CHD. In 2019, it is estimated that 720,000 Americans will have a new AMI, and 335,000 will have a recurrent event [1]. Nearly $35 \%$ of patients who experience a CHD event yearly will die from it, and $\approx 15 \%$ who develop AMI will die of it [1]. In Jordan, 131 deaths per 100,000 are due to CHD, accounting for nearly $20 \%$ of all deaths [3].

In the US, during the period from 2001 and 2011, inhospital mortality after ST segment elevation myocardial infarction (STEMI) increased for patients without any intervention, did not change for patients who received percutanous coronary intervention, and decreased for patients who had coronary artery bypass surgery [1]. Therefore, determining physiological and psychological factors affecting mortality and morbidity for patients with STEMI is warranted.

Psychological manifestations after AMI are very common, with the most common being depression and anxiety. The incidence of depression after AMI might be as high as $80 \%[4,5]$. Previous studies have found evidence that depression is associated with short- and long-term complications after AMI. In the short term, starting as early as the first 20 min after AMI [6-9], depression was an independent predictor of complications such as acute recurrent ischemia, re-infarction, ventricular tachycardia, ventricular fibrillation, cardiogenic shock, pulmonary edema, inflammation (i.e., endocarditis), left ventricular mural thrombus, and in-hospital death [3, 4, 6, 7, 10]. Moreover, high levels of depression were associated with higher levels of fatigue and longer hospitalization, especially in critical care units [4], and lower levels of left ventricular ejection fraction (LVEF) [11].

Over the long term, depression is a more significant predictor than traditional risk factors such as smoking and hyperlipidemia for adverse outcomes after AMI [12, 13]. Depression was associated with increased risk of reinfarction, readmissions $[14,15]$, and ischemic cardiac events [16-18]. Moreover, in longitudinal studies (up to 10 years post-event) depression increased morbidity and mortality after AMI [19, 20]. In addition, depression played a significant role of incomplete recovery [21], poor quality of life $[22,23]$, postponing return to work [24], lack of adherence to medication and health care team instructions [25], and not following the rehabilitation protocols after AMI [26].

The effect of depression on cardiac mortality after AMI was assessed in a scientific statement from the American Heart Association based on their analysis of 11 studies. A significant relationship was reported in 8 studies [27]. Based on the results of their analysis, the American Heart Association reinforced their appraisal of depression as a risk factor for complications and mortality after AMI [27]. Patients' coping, psychosocial repossession, and quality of life after AMI depends on psychological (i.e., depression) instead of physiological factors $[3,28]$. It has been shown that personal control and social support have protective effects against depression, and improve quality of life in different cardiac populations [29, 30]. Therefore, if depression is assessed and managed well for patients with AMI, this might improve their outcomes and decrease complications.

Perceived control (PC) is a new strategy under investigation that might have a protective effect against depression in patients with AMI. It has been defined as "an individual's belief that he or she has the resources required to cope with negative events in a way that positively influences their adversive nature" [28]. To our knowledge, no studies were specifically designed to check the effect of PC on depression and in-hospital complications in patients with AMI. However, different studies investigated the relationship between $\mathrm{PC}$ and anxiety, finding that $\mathrm{PC}$ was negatively associated with anxiety in AMI, cardiac surgery, and heart failure [28]; moreover, it was an independent predictor of anxiety in these populations, and moderated the relationship between anxiety and in-hospital complications [3, 31]. Therefore, the major purpose of this study was to check if there is a moderating effect of $\mathrm{PC}$ on the relationship between depression and in-hospital complications after STEMI.

\section{Methods}

\section{Research design, sample, and setting}

This study employed a prospective, non-experimental, observational design, recruiting participants from one governmental and two private hospitals in Amman. Inclusion criteria comprised: (1) cardiology STEMI diagnosis (confirmed), with increased enzyme and cardiac changes (indicated by ECG); (2) adult patients (aged over 18 years); (3) not in unusual pain and stable hemodynamically at the time of interview; (4) able to give (and sign) informed consent and to participate by answering questionnaire items; and (5) not suffering from critical comorbidities and serious non-cardiac conditions (e.g. stroke, sepsis, and shock). Exclusion criteria included those who prior to $\mathrm{PC}$ or depression 
manifested in-hospital complications, in order to explore the longitudinal, cause-and-effect dimension of the clinical problem.

A logistic regression sample-size calculator was used a priori to ensure that the findings would have significance statistically. Criteria included estimated event rate (occurrence of complications) of 27\% [31], two-tailed test with power of 0.8 , and alpha of 0.05 . Regression analysis was conducted with 13 independent variables. The consequent requirement was 238 participants, thus 300 participants were included to account for dropout and attrition etc. (Fig. 1).

\section{Ethical considerations}

The Applied Science Private University Amman's Institutional Review Board (IRB) Committee analyzed this study and accorded it their ethical approval (IRB\#: Faculty 024). Consequently, the University President formally requested that the hospital directors enable and assist the fieldwork. Subsequently, the medical directors in the studied settings were met by the principal investigator to ensure their acknowledgement and cooperation with the approval letter, and they issued their own permission to begin data collection and to apply the study fieldwork.

\section{Procedure}

Research assistants (RAs) were engaged to collect data from hospitals, with critical care nursing master's degrees, and training in cardiovascular care. Each potential participant in the studied settings who met the inclusion criteria was approached by the RAs, who explained the study to them in depth, along with all pertinent ethical information (e.g. voluntary participation and right to withdraw etc.), and those who subsequently wished to take part were asked to sign a form indicating their informed consent. Participants were interviewed while hemodynamically stable during their initial 3 days following admission (mean \pm SD; $35 \pm 16 \mathrm{~h}$ ). Socio-demographic information was recorded by the RAs, who also delivered the Control Attitude Scale-Revised (CAS-R) and the depression subscale of the Hospital Anxiety and

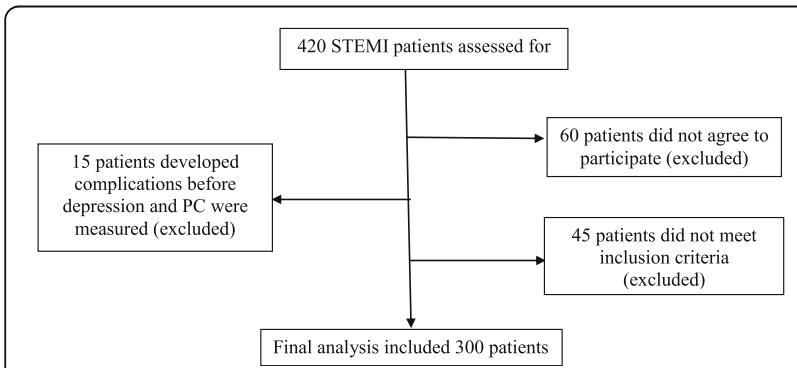

Fig. 1 Patient flow diagram. A total of 300 patients were included in the final analyses PC: Perceived control.
Depression Scale (HADS). Upon discharge, RAs noted from participants' medical records their in-hospital complications (if applicable) along with any other pertinent comorbidities.

\section{Measurement of variables}

\section{- Clinical and Socio-Demographic Characteristics}

As mentioned previously, following participants' discharge from hospital (i.e. upon completion of their inpatient treatment), the RAs extracted socio-demographic and clinical data from their medical records, including gender, age, smoking profile, vital signs upon admission and chest pain severity, and experience of diabetes mellitus, emergency and ICU medications, hypertension, LVEF, and myocardial infarction.

\section{- Depression}

Arabic HADS was used to assess depression. Numerous cardiac studies affirm its psychometric proprieties (Cronbach's $\alpha 0.87)[6,32-35]$. The seven items are rated on a four-point Likert scale, ranging from 0 to 3, where 3 refers to the maximum severity and frequency of symptoms. The values assigned for each item add up to a net score ranging from 0 to 21 , which are then classified according to depression severity as normal $(0-7)$, mild $(8-10)$, moderate (11-14), and severe (15-21) [6,32].

\section{- In-Hospital Complications}

STEMI frequently results in in-hospital complications $[3,4,7,8,31]$, of which the following are common: (a) ventricular fibrillation; (b) ventricular tachycardia warranting care, particularly $\geq 30 \mathrm{~s}$ (attributable to hemodynamic instability); (c) acute recurrent ischemia; (d) cardiogenic shock; (e) reinfarction; (f) acute pulmonary edema; and (g) mortality.

\section{- Perceived Control}

Arabic CAS- $\mathrm{R}$ was deployed to measure PC, having displayed acceptable psychometric proprieties among cardiac populations. Hypothesis testing has displayed its construct validity for known associations, and its reliability and validity have been demonstrated among 500 STEMI participants (Cronbach's $\alpha$ 0.85) [3]. The tool comprises eight items answerable with Likert-type scales, with responses descending from 5 "totally agree" to 1 "totally disagree". Net scores are in the range of 8-40, with lower scores denoting lower PC levels. Due to the lack of mean norms, other researchers deployed median values as delimitation points [3, 31]; following this 
method, the resultant median in this study was set as the cut-off point (29), whereby participants with higher scores for PC had high PC, and vice-versa.

\section{Data analysis}

Data analysis was conducted with recourse to SPSS (version 24). Statistical significance was denoted by $p$ value $<.05$. Clinical and socio-demographic characteristics related to depression changes at baseline were described by frequencies, percentages, and Mean $\pm \mathrm{SD}$. Continuous and categorical variables were analyzed using Student's $\mathrm{t}$-test or $\mathrm{X}^{2}$, respectively, to ensure that the studied variables were pertinent to the research. Variables differing between the high and low depression groups could thus be controlled for the purposes of subsequent analyses.

To control for the other variables and to determine the impacts of $\mathrm{PC}$, depression, and interaction term (moderating effect), multiple hierarchal logistic regression was deployed, yielding results as odds ratios and 95\% confidence intervals. Three blocks were applied for regression: (1) age and gender; (2) history of diabetes, emergency department medication (e.g. beta block, aspirin, or anti-depressant), hypertension, LVEF, previous myocardial infarction, and smoking; and (3) PC and depression scores, and depression"PC interaction. Multicollinearity between variables was absent, as indicated by variance inflation factor (less than 3 ).

\section{Results}

\section{Socio-demographic and clinical characteristics}

The sample consisted of a total 300 participants, including 231 men and 69 women. During hospitalization, 72 participants $(24 \%)$ developed at least one complication (Table 1). Patients with high depression scores (8-21) were more likely to develop complications $\left(x^{2}=34.15\right.$, $p<.001)$ than those with low depression scores $(0-7)$. Moreover, they have lower levels of LVEF (M [SD], 44.60 [7.31] vs. 53.05 [7.12], $\mathrm{p}<.001)$. Patients with high levels of PC had lower levels of depression than those with low PC (M [SD], 9.47 [6.43] vs. 12.31 [6.66], p <.001). Sociodemographic and clinical characteristics relative to

Table 1 Specific complications developed and their percentages

\begin{tabular}{ll}
\hline Complication developed & ${ }^{a}$ Number of patients (\%) \\
\hline Acute recurrent ischemia & $30(41.7)$ \\
Pulmonary edema & $10(13.9)$ \\
Sustained ventricular tachycardia & $9(12.5)$ \\
Re-infarction & $8(11.1)$ \\
Cardiogenic shock & $7(9.7)$ \\
In-hospital death. & $3(4.2)$ \\
Ventricular fibrillation & $2(2.8)$ \\
\hline
\end{tabular}

${ }^{\mathrm{a}}$ More than one patient developed more than one complication depression levels are presented in Table 2. Only one clinical variable differed between low and high depression groups: patients in the high depression group received anti-depressant medication more frequently than those in the low depression group Table 3. There were no differences in any socio-demographic or clinical variables between those who continued the study and those who dropped out.

\section{Checking the moderating effect}

The results of the logistic regression are presented in Table 4. The model shows five significant predictors: history of previous AMI, depression scores, PC scores, LVEF, and the interaction between depression and PC. Perceived control moderated the association between depression and complications since depression scores, PC scores, and the interaction between depression and PC were significant predictors of complications. Participants with high depression and low PC have the highest rate of complications $(31.5 \%$ vs. $15.4 \%, p<.001)$ (Fig. 2).

\section{Other important findings}

Previous myocardial infarction and high levels of depression increased the occurrence of complications by 121 and 51\%, respectively. High levels of PC have a protective effect against complications by $19 \%$. Moreover, high levels of LVEF have a protective effect against complication by $17 \%$.

\section{Discussion}

This pioneering investigation demonstrates that PC moderates depression related to post-STEMI complications in in-hospital settings in a developing country. In other words, the results demonstrate that PC moderates post-STEMI in-hospital complications in relation to

Table 2 Sociodemographic and clinical characteristics of the sample based on depression levels $(N=300)$

\begin{tabular}{lll}
\hline Characteristic & $\begin{array}{l}\text { High Depression } \\
(n=195)\end{array}$ & $\begin{array}{l}\text { Low Depression } \\
(n=105)\end{array}$ \\
\hline Age & $69.5 \pm 9.0$ & $69.02 \pm 10.0$ \\
Gender & $149(76.4)$ & $82(78.1)$ \\
$\quad$ Male & $46(23.6)$ & $23(21.9)$ \\
$\quad$ Female & $80(41.0)$ & $49(46.7)$ \\
History of DM & $155(79.5)$ & $86(81.9)$ \\
History of HTN & $122(62.6)$ & $75(71.4)$ \\
History of previous AMI & $146(74.9)$ & $83(79.0)$ \\
History of smoking & $5.17 \pm 2.2$ & $5.26 \pm 2.2$ \\
Severity of chest pain & $44.6 \pm 7.3$ & $53.05 \pm 7.1^{* *}$ \\
Ejection fraction & $59(30.3)$ & $48(18.8)^{* *}$ \\
Development of complications &
\end{tabular}

Values are presented as $\mathrm{M} \pm \mathrm{SD}$ or $\mathrm{n}(\%), D M$ Diabetes Miletus, HTN Hypertension, $A M I$ Acute myocardial infarction, ${ }^{* *}$ significant at $P<.001$ 
Table 3 Treatment received during hospitalization $(N=300)$

\begin{tabular}{lll}
\hline Treatment & $\begin{array}{l}\text { High Depression } \\
(\mathrm{n}=195)\end{array}$ & $\begin{array}{l}\text { Low Depression } \\
(\mathrm{n}=105)\end{array}$ \\
\hline Thrombolytic agents & $80(41.0)$ & $37(35.2)$ \\
Beta blocker & $98(50.3)$ & $50(47.6)$ \\
Aspirin & $175(89.7)$ & $90(85.7)$ \\
Anti-depressant & $113(58.0)$ & $42(40.0)^{*}$ \\
Coronary artery bypass graft & $20(10.3)$ & $12(11.4)$ \\
Angioplasty & $119(61.0)$ & $67(63.8)$ \\
\hline
\end{tabular}

Values are presented as $\mathrm{n}(\%) .{ }^{*}$ significant at $P<.05$

psychological symptoms (i.e. depression and anxiety) $[3,31]$. Depression and PC were both independent predictors of these complications, affirming the findings of previous studies on the former predictor [4-6, 36]: PC militates against depression, while the latter predisposes patients to such complications, the most prolific of which was acute recurrent ischemia [3, 4, 7, 8, 31]. Approximately one-quarter $(24 \%)$ of participants in this study developed some form of complication.

This study thus affirms previous investigations finding relatively high prevalence of in-hospital complications following STEMI, contrary to research that found no significant link between in-hospital complications and depression [37-41]. Numerous potential reasons for these divergent findings can be postulated, including differing operational definitions of depression itself, different data collection techniques (e.g. timing of depression evaluation), different sample sizes, and a lack of regard for depression moderators. Depression-measuring tools may have wide indications spanning numerous forms of illness, including subclinical CHD. In this study, HADS was used to measure depression, to differentiate depression among physically ill patients, which removes somatic indications that can obscure factors of heart disease but which may blunt depression detection $[3,6,35]$. As a result, this study is conservative in its estimation of the significance of the relationship between in-hospital complications and depression.

There are numerous possible causes of the link between complications and depression. For instance, physiologically, the experience of depression inhibits para-sympathetic neuronal activity, and activates sympathetic nervous activity, which gives a fillip to activities conducive to complications (e.g. inflammation, fibrillation threshold changes, decreased variability in heart rate, and increased aggregation of platelets) [2, 6, 8, 31]. Initial proliferation of such physiological variables immediately after AMI is highly linked to the development of complications $[2,6,8,31]$. In terms of behavior, depression is linked to reduced enthusiasm, exercise, and healthy eating, and increased smoking and other unhealthy behaviors $[3,28,31]$, albeit these usually play a minimal role in the experience of acute clinical/ health events [3, 28, 31].

Depression experienced during or in the wake of dangerous or critical events and experiences can be moderated by $\mathrm{PC}$ to reduce in-hospital complications, particularly in terms of improving coping skills [31, 42], and reducing anxiety, whose mechanisms are similar to depression [31, 42]. This entails that the association between in-hospital complications and anxiety is strong when PC is low, and vice-versa. Consequently, increased PC reduces in-hospital complications and creates a protective cardiac impact: it reduces anxiety and stimulation of the sympathetic nervous system, supporting parasympathetic nervous activity $[31,42]$, thus guarding from complications.

The empirical results of this study support general conclusions reached by previous researchers, and are of potential clinical importance with regard to depression being associated with lower LVEF [11]; every increase in LVEF units increases by $17 \%$ the protective effect against in-hospital complications [3, 28, 31]. Improved quality of life among STEMI patients is also linked to higher LVEF, thus enhancing the latter may improve the former, which may also control depression, high levels of which correspond to low prevalence of LVEF. The results of this investigation thus affirm the moderating role of PC on depression and improved LVEF.

\section{Conclusions}

In patients with STEMI, depression is associated with increased risk of complications in the early phase. Perceived control has a protective and moderating effect on

Table 4 Logistic regression analysis for predictors of in-hospital complications

\begin{tabular}{lllll}
\hline Predictor & Odds ratio & Wald & $95 \% \mathrm{Cl}$ & $\mathrm{p}$ value \\
\hline History of previous AMI & 2.21 & 8.61 & $1.51-4.31$ & $1.11-2.01$ \\
Depression scores & 1.51 & 7.70 & 005 \\
Perceived control & 0.81 & 7.01 & $0.75-0.99$ & .007 \\
LVEF & 0.83 & 6.22 & $0.71-0.96$ & .008 \\
Depression scores * Perceived control & 1.61 & 8.31 & $1.22-2.21$ & .030 \\
\hline
\end{tabular}

AMI Acute myocardial infarction, Cl Confidence interval, LVEF Left ventricular ejection fraction. Variables used in the model (age, gender, history of diabetes, history of hypertension, history of smoking, history of previous $\mathrm{AMI}_{\text {, }}$, beta blocker use, anti-depressant use, aspirin use, left ventricular ejection fraction, depression scores, perceived control scores, and the interaction between depression and perceived control) 


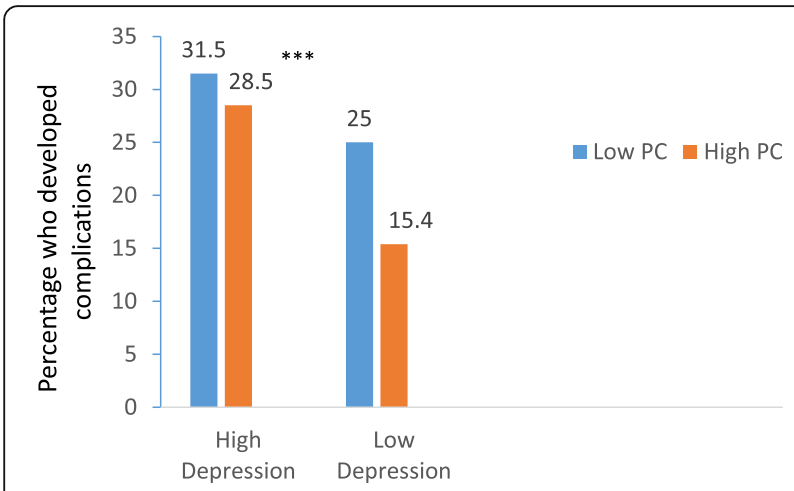

Fig. 2 Comparison of percentage of patients who developed complications based on depression levels and PC. Patients with high depression and low PC had the highest complication rate indicating the moderating level of PC on the relationship between depression and complications. ${ }^{* * *} \mathrm{p}<.001$. Abbreviation: PC, perceived control.

this relationship. Assessment of depression and enhancement of PC in this group might decrease complications, morbidity, and mortality.

\section{Limitations}

The major limitation of this study was the exclusion of hemodynamically unstable patients, which might decrease the incidence of in-hospital complications. Moreover, data were collected from one major city in Jordan, which might limit the generalizability of the results.

\section{Abbreviations}

AMI: Acute myocardial infarction; CAS-R: Control attitude scale revised; CHD: Coronary heart disease; CVDs: Cardiovascular diseases; HADS: Hospital anxiety and depression scale; IRB: Institutional review board; LVEF: Left ventricular ejection fraction; PC: Perceived control; RA: Research assistant; STEMI: ST-segment elevation myocardial infarction

\section{Acknowledgements}

I wish to thank research assistants who helped in the data collection for this research project.

\section{Authors' contributions}

This is a single author manuscript. The author read and approved the final manuscript.

\section{Funding}

This is a personal research without any type of funding.

\section{Availability of data and materials}

The datasets used and/or analyzed during the current study available from the corresponding author on reasonable request.

\section{Ethics approval and consent to participate}

Approval was granted by the IRB committee at the Applied Science Private University. All participants signed a written informed consent.

\section{Consent for publication}

Not applicable.

\section{Competing interests}

The authors declare that they have no competing interests.
Received: 18 January 2019 Accepted: 6 June 2019

Published online: 13 June 2019

\section{References}

1. Benjamin EJ, Virani SS, Callaway CW, Chamberlain AM, Chang AR, Cheng S, Chiuve SE, Cushman M, Delling FN, Deo R, et al. Heart disease and stroke Statistics-2018 update: a report from the American Heart Association. Circulation. 2018;137(12):e67-e492.

2. AbuRuz ME, Masa'Deh R. Gender differences in anxiety and complications early after acute myocardial infarction. J Cardiovasc Nurs. 2017;32(6):538-43.

3. AbuRuz ME. Perceived control moderates the relationship between anxiety and in-hospital complications after ST segment elevation myocardial infarction. J Multidiscip Healthc. 2018;11:359-65.

4. AbuRuz ME, Alaloul F, Al-Dweik G. Depressive symptoms are associated with in-hospital complications following acute myocardial infarction. In: Applied nursing research : ANR 2018, vol. 39. p. 65-70.

5. Thombs BD, Bass EB, Ford DE, Stewart KJ, Tsilidis KK, Patel U, Fauerbach JA, Bush DE, Ziegelstein RC. Prevalence of depression in survivors of acute myocardial infarction. J Gen Intern Med. 2006;21(1):30-8.

6. AbuRuz ME, Al-Dweik G. Depressive symptoms and complications early after acute myocardial infarction: gender differences. Open Nurs J. 2018;12:205-14

7. Abed MA, Frazier S, Hall LA, Moser DK. Anxiolytic medication use is not associated with anxiety level and does not reduce complications after acute myocardial infarction. J Clin Nurs. 2013;22(11-12):1559-68.

8. Abu Ruz ME, Lennie TA, Moser DK. Effects of beta-blockers and anxiety on complication rates after acute myocardial infarction. Am J Crit Care. 2011; 20(1):67-73 quiz 74

9. Moser DK, Dracup K. Is anxiety early after myocardial infarction associated with subsequent ischemic and arrhythmic events. Psychosom Med. 1996; 58(5):395-401.

10. Grewal K, Stewart DE, Abbey SE, Leung YW, Irvine J, Grace SL. Timing of depressive symptom onset and in-hospital complications among acute coronary syndrome inpatients. Psychosomatics. 2010;51(4):283-8.

11. Bagherian-Sararoudi R, Gilani B, Ehsan HB, Sanei H. Relationship between left ventricular ejection fraction and depression following myocardial infarction: An original article. Arya Atheroscler ARYA Atherosclerosis. 2013;9(1).

12. Goldston K, Baillie AJ. Depression and coronary heart disease: a review of the epidemiological evidence, explanatory mechanisms and management approaches. Clin Psychol Rev. 2008;28(2):288-306.

13. Steptoe A, Brydon L. Emotional triggering of cardiac events. Neurosci Biobehav Rev. 2009;33(2):63-70.

14. Reese RL, Freedland KE, Steinmeyer BC, Rich MW, Rackley JW, Carney RM. Depression and rehospitalization following acute myocardial infarction. Circ Cardiovasc Qual Outcomes. 2011:4(6):626-33.

15. Wu Q, Kling JM. Depression and the risk of myocardial infarction and coronary death: a meta-analysis of prospective cohort studies. Medicine (Baltimore). 2016;95(6):e2815.

16. Meijer A, Conradi HJ, Bos EH, Thombs BD, van Melle JP, de Jonge P. Prognostic association of depression following myocardial infarction with mortality and cardiovascular events: a meta-analysis of 25 years of research. Gen Hosp Psychiatry. 2011;33(3):203-16.

17. Bekke-Hansen S, Trockel M, Burg MM, Taylor CB. Depressive symptom dimensions and cardiac prognosis following myocardial infarction: results from the ENRICHD clinical trial. Psychol Med. 2012;42(1):51-60.

18. Denollet J, Martens EJ, Smith OR, Burg MM. Efficient assessment of depressive symptoms and their prognostic value in myocardial infarction patients. J Affect Disord. 2010;120(1-3):105-11.

19. van Dijk MR, Utens EM, Dulfer K, Al-Qezweny MN, van Geuns RJ, Daemen J, van Domburg RT. Depression and anxiety symptoms as predictors of mortality in $\mathrm{PCl}$ patients at 10 years of follow-up. Eur J Prev Cardiol. 2016; 23(5):552-8.

20. Du J, Zhang D, Yin Y, Zhang X, Li J, Liu D, Pan F, Chen W. The personality and psychological stress predict major adverse cardiovascular events in patients with coronary heart disease after percutaneous coronary intervention for five years. Medicine (Baltimore). 2016;95(15):e3364.

21. Lesperance F, Frasure-Smith $N$, Juneau $M$, Theroux $P$. Depression and 1-year prognosis in unstable angina. Arch Intern Med. 2000;160(9):1354-60.

22. Beck CA, Joseph $L$, Belisle P, Pilote L. Predictors of quality of life 6 months and 1 year after acute myocardial infarction. Am Heart J. 2001;142(2):271-9.

23. de Jonge $P$, Spijkerman TA, van den Brink RH, Ormel J. Depression after myocardial infarction is a risk factor for declining health related quality of 
life and increased disability and cardiac complaints at 12 months. Heart. 2006;92(1):32-9.

24. Soderman E, Lisspers J, Sundin O. Depression as a predictor of return to work in patients with coronary artery disease. Soc Sci Med. 2003;56(1):193-202.

25. Lin EH, Katon W, Von Korff M, Rutter C, Simon GE, Oliver M, Ciechanowski P, Ludman EJ, Bush T, Young B. Relationship of depression and diabetes selfcare, medication adherence, and preventive care. Diabetes Care. 2004;27(9): 2154-60.

26. Leifheit-Limson EC, Kasl SV, Lin H, Buchanan DM, Peterson PN, Spertus JA, Lichtman JH. Adherence to risk factor management instructions after acute myocardial infarction: the role of emotional support and depressive symptoms. Ann Behav Med. 2012;43(2):198-207.

27. Lichtman JH, Froelicher ES, Blumenthal JA, Carney RM, Doering LV, FrasureSmith N, Freedland KE, Jaffe AS, Leifheit-Limson EC, Sheps DS, et al. Depression as a risk factor for poor prognosis among patients with acute coronary syndrome: systematic review and recommendations: a scientific statement from the American Heart Association. Circulation. 2014;129(12): 1350-69.

28. Moser DK, Riegel B, McKinley S, Doering LV, Meischke H, Heo S, Lennie TA, Dracup K. The control attitudes scale-revised: psychometric evaluation in three groups of patients with cardiac illness. Nurs Res. 2009;58(1):42-51.

29. Kidd T, Poole L, Leigh E, Ronaldson A, Jahangiri M, Steptoe A. Health-related personal control predicts depression symptoms and quality of life but not health behaviour following coronary artery bypass graft surgery. J Behav Med. 2016;39(1):120-7.

30. Alaloul F, AbuRuz ME, Moser DK, Hall LA, Al-Sadi A. Factors associated with quality of life in Arab patients with heart failure. Scand I Caring Sci. 2017; 31(1):104-11.

31. Moser DK, Riegel B, McKinley S, Doering LV, An K, Sheahan S. Impact of anxiety and perceived control on in-hospital complications after acute myocardial infarction. Psychosom Med. 2007;69(1):10-6.

32. Bjelland I, Dahl AA, Haug TT, Neckelmann D. The validity of the hospital anxiety and depression scale. An updated literature review. J Psychosom Res. 2002;52(2):69-77.

33. el-Rufaie OE, Absood G. Validity study of the hospital anxiety and depression scale among a group of Saudi patients. Br J Psychiatry. 1987;151: 687-8.

34. el-Rufaie OE, Albar AA, Al-Dabal BK. Identifying anxiety and depressive disorders among primary care patients: a pilot study. Acta Psychiatr Scand. 1988;77(3):280-2.

35. el-Rufaie $\mathrm{OE}$, Absood GH. Retesting the validity of the Arabic version of the hospital anxiety and depression (HAD) scale in primary health care. Soc Psychiatry Psychiatr Epidemiol. 1995;30(1):26-31.

36. Shang YX, Ding WQ, Qiu HY, Zhu FP, Yan SZ, Wang XL. Association of depression with inflammation in hospitalized patients of myocardial infarction. Pak J Med Sci. 2014;30(4):692-7.

37. McKinley S, Fien M, Riegel B, Meischke H, Aburuz ME, Lennie TA, Moser DK. Complications after acute coronary syndrome are reduced by perceived control of cardiac illness. J Adv Nurs. 2012;68(10):2320-30.

38. Lane D, Carroll D, Ring C, Beevers DG, Lip GY. Effects of depression and anxiety on mortality and quality-of-life 4 months after myocardial infarction. J Psychosom Res. 2000;49(4):229-38.

39. Mayou RA, Gill D, Thompson DR, Day A, Hicks N, Volmink J, Neil A Depression and anxiety as predictors of outcome after myocardial infarction. Psychosom Med. 2000;62(2):212-9.

40. Nakamura S, Kato K, Yoshida A, Fukuma N, Okumura Y, Ito H, Mizuno K. Prognostic value of depression, anxiety, and anger in hospitalized cardiovascular disease patients for predicting adverse cardiac outcomes. Am J Cardiol. 2013;111(10):1432-6.

41. Welin C, Lappas G, Wilhelmsen L. Independent importance of psychosocial factors for prognosis after myocardial infarction. J Intern Med. 2000;247(6): 629-39.

42. Moser DK, Dracup K. Impact of cardiopulmonary resuscitation training on perceived control in spouses of recovering cardiac patients. Res Nurs Health. 2000;23(4):270-8

\section{Publisher's Note}

Springer Nature remains neutral with regard to jurisdictional claims in published maps and institutional affiliations.

\section{Ready to submit your research? Choose BMC and benefit from}

- fast, convenient online submission

- thorough peer review by experienced researchers in your field

- rapid publication on acceptance

- support for research data, including large and complex data types

- gold Open Access which fosters wider collaboration and increased citations

- maximum visibility for your research: over $100 \mathrm{M}$ website views per year

At BMC, research is always in progress.

Learn more biomedcentral.com/submissions 